\title{
THEORY-ORIENTED EVALUATION FOR THE DESIGN AND RESEARCH OF GAMING AND SIMULATION
}

This is a post/pre-print of an article submitted for consideration in the Simulation \& Gaming (C) 2006 SAGE Publications.

Personal use of this manuscript is permitted. Permission from SAGE Publications must be obtained for any other commercial purpose.

This article may not exactly replicate the published version, due to editorial changes and/or formatting and corrections during the final stage of publication. Interested readers are advised to consult the published version which can be found at:

http://sag.sagepub.com/content/37/2/268.abstract

doi: $\{10.1177 / 1046878106287950\}$

Please refer this manuscript as:

Kriz, W. C., \& Hense, J. U. (2006). Theory-oriented evaluation for the design of and research in gaming and simulation. Simulation \& Gaming, 37(2), 268-283. 


\title{
Theory-oriented evaluation for the design and research of gaming and simulation
}

\author{
Willy Christian Kriz \\ University of Applied Sciences Vorarlberg, Austria \\ Jan Ulrich Hense \\ Ludwig Maximilians University, Munich, Germany
}

\begin{abstract}
Jan Klabbers introduced the terms science of analysis and science of design to indicate differences between the communities of theoretical research with gaming simulation and the game design practitioners. The science of analysis uses games and simulations as research methods to test theories in various fields. Accordingly, the external validity of findings is the most important criterion of success. Research in the science of design perspective emphasizes the design of the artifact, and testing its usability. "Usability" refers to the idea of designing artifacts for clearly-specified contexts of use for clearly-identified audiences. However, the way both communities are interconnected and in which ways they can be of mutual benefit remains puzzling and controversial. It is our aim to discuss the potential contributions of theory-based evaluation in order to link both communities. Theory-oriented evaluation approaches are based on logic models which have the function of outlining how the simulation, its participants, and its environment interact with each other, and elicit the simulation's desired outcomes. In evaluation studies, logic models are primarily used to support the planning of the evaluation design, and to provide a framework for interpreting evaluation findings. Thus, theory-oriented evaluations go beyond mere outcome-evaluations not only because they take the effects of a simulation session into consideration, but also because they aspire to identify the crucial factors which cause or moderate such effects. For this purpose, theory-oriented evaluation is assigned to the design science tradition. Its primary aim is to gain evaluative knowledge from a particular gaming simulation which can then be used to improve the simulation and its implementation for practical purposes. We will illustrate our viewpoints by discussing the theory-oriented evaluation of SIMGAME, a simulation game for business education in secondary schools.
\end{abstract}

KEYWORDS: design science, analytical science, theory-oriented evaluation, logic model, project example

There has been much criticism in the area of gaming and simulation research due to the disparity between conventional academic research and research based on practical experience. The conventional academic research carried out in this field has focused on developing and improving domain-specific knowledge by using simulation games in experimental environments (gaming and simulation laboratories). In contrast, the practical experience in this field has involved the transfer and dissemination of knowledge using specific simulation games with clearly-defined designated audiences in a defined context of use. Klabbers (2004) uses the terms science of analysis and science of design to describe these two different approaches. The theory-driven science of analysis approach has used games and simulations as scenarios to test theories in various domains such as education, social psychology, politics and economics. The main aim of the conventional science of analysis has been to develop generalized scientific concepts and context-independent knowledge. Accordingly, the external validity of findings is of primary importance to this approach. Research in the issue-driven science of design approach, on the other hand, puts the emphasis on the usability of the simulation game. In this case, games and simulations are studied with the aim of supporting and evaluating their development and use in practical contexts. Here it is necessary to focus on local knowledge and individual, unique circumstances in order to find customized solutions to practical problems. The science of design has two branches (Klabbers, 2003): Design-in-the-small, which uses simulation games as artifacts to model processes of reality, and design-in-the-large, which uses the effects of simulation games to 
change existing dysfunctional situations, patterns of behavior or systems structures into preferential ones. Therefore, it is essential that the artifact assessment takes the evaluation of a simulation game as a product into account, as well as its impact on the process of change. In the design science, the interplay of design-in-the-small, and design-in-the-large is of primary importance.

Although we view both the science of analysis and the science of design as legitimate approaches to gaming and simulation, the question still remains how both approaches are to be interconnected and how each can benefit from the other's expertise. Both science traditions reach agreement in the area of gaming simulation, yet confusion and misunderstanding between representatives of both communities continues to cause conflict. It appears that representatives of both parties are reluctant to actively work together. As a consequence of this conflict of interests, a potentially fruitful exchange of ideas is failing to occur. One major cause for the obvious oppositional stance of both traditions - which Klabbers has described in the introduction of this journal as a contradiction between the communities of observers and communities of practice - has its roots in the different epistemologies and methodologies, as well as in practical terms as both communities use different criteria for success. Since we - as authors - belong to the scientific community of applied psychology, we sometimes experience this frustrating antagonism in our practise. In our case the main criterion of success consists in the amount of new research findings and scientific publications, which have to meet the specific standards of the science of analysis tradition as well as those of empirical social research. On the other hand, we develop and evaluate concrete simulation games, which are solely regarded successful by our customers if they can realize advantages and learning effects, and when intended changes of human behavior can be triggered and/or changes of organizational structures and work processes are supported.

Regarding Klabbers' depicted framework in the introduction of this issue of the journal, we take a position in between of both traditions, as well as use the intersecting set of both of them. It is a position which requires the special commitment to both parties, on the other hand also puts us at the risk of being misunderstood by both sides. However, especially in our discipline of educational and organizational psychology, the optimization of learning environments (e.g. in the vocational education processes) is a legitimate and common area of research. Here, applied (analytical) science and concrete requirements of practice encounter each other and are being linked by the so-called "design based research". In this paper it is our aim to discuss the potential contributions of theory-oriented evaluation to bridge the gap between both communities. To do so, we will give a short overview of theory-based evaluation approaches in the following section.

\section{Theory Based Evaluation of Gaming Simulation with Logic Models}

The main aim of theory-oriented evaluation approaches is to go beyond testing the outcomes of gaming simulations in respect to meeting their learning goals. The goal is not only to prove whether a simulation works but also to show how and why it works (or fails to work) in a given context. So-called logic models, which are also sometimes referred to as program models, program logics or program theories are important tools to accomplish these goals (Bickman, 1987). Logic models depict how relevant variables and their interaction lead to the desired and unintentional outcomes of gaming simulations. They normally differentiate at least between inputs (preconditions), processes (actions), as well as outputs/outcomes (effects), and describe the mutual relationships between these variables. Logic models rely heavily on theoretical considerations and knowledge in the domain of the artifact that is to be evaluated. Thus, in the case of evaluating gaming simulations, evaluators should have considerable knowledge about practical application, and it is often advisable for them to cooperate with the practitioners who develop and/or facilitate the game. Such preconditions 
imply that by using logic models it is not enough to refer only to abstract, disembodied theories, as is common in the analytical science domain. Actually, we are also referring to "theories-in-use", which puts this approach at the same time into the domain of design science.

There has been a call for a more explicit use of theory in evaluation for some time now in the general field of evaluation research. Early theorists criticized a tendency in evaluation to concentrate solely on the outputs and outcomes of a program. Suchman (1967), for example, proposed to conceptualize the processes and mediating factors in carrying out an evaluation. The term "program model" goes back to Weiss (1972), while Fitz-Gibbon and Morris (1975) were the first to introduce the term "theory-based evaluation". Yet, it took until the 1980s until theory-based approaches came to life as fully-fledged evaluation models (Chen \& Rossi, 1983) and gained wide acceptance in the field (e. g. Bickman, 1987; Chen \& Rossi, 1992; Rossi, Lipsey \& Freeman, 2004). Only recently, the authors have suggested applying theory-oriented approaches for the evaluation of gaming and simulations in their context of use (Hense, 2004; Kriz \& Hense, 2004; Hense \& Kriz, 2005).

What was the motivation for these developments? Chen (1990) denounced common evaluation practice as 'black-box evaluations'. Similar to behavioristic learning theories, black box evaluations observe only the inputs and outputs of an artefact, neglecting the intermediate relationships and mechanisms. This deficit goes back to restrictions of the classical quasi-experimental research design, which has its undisputed merits in determining the effects of programs, yet often fails to deliver information needed for improvement and implementation of a program. Moreover, in the domain of gaming and simulation - with its close ties to system dynamics - this kind of simplified view of social realities seems inappropriate.

To illustrate how the basic ideas of using logic models in evaluation are put into practice, one can refer to the comprehensive approach by Reynolds (1998). He distinguishes seven steps in conducting a theory-based evaluation, which can easily be adapted to the evaluation of gaming simulations. The first step is to develop a logic model for the game or simulation which is to be evaluated. Here, it is important to distinguish between two levels. In most cases, simulations are already based on a model which mimics a specific part of reality, dependent upon the domain of the simulation. In the case of a simulation for the teaching of ecological awareness, for example, this model could depict an ecosystem, its various components, and their interdependencies. However, the logic model needed for evaluation purposes is a different one. It models the usage and application of the game or simulation for learning or other purposes in a given educational context such as biology lessons in schools. In the given example, this model would basically depict relevant antecedents, learning processes and outcomes, which contribute to the desired goal of increased ecological awareness and competence. The second step is to measure the effects of participation in the simulation with regard to the logic model's outcomes. This is in accordance with traditional evaluations. In a third step, data is collected on mediating and background factors. They are also derived from the logic model. For the example used above, one would probably include learner characteristics such as previous knowledge and attitudes, or process variables such as joint strategic decisions and interactions impacting on the ecosystem in the simulation. The fourth step consists of estimating the main effects of participation (interactions and events) and the fifth tests causal mechanisms of the logic model (as a dynamic artifact) to explain these effects. Here is where the theoretical approach can show one of its most important merits: in addition to learning about the effects of the game, the logic model can be used to analyze which factors contributed the most, and which factors had a detrimental effect. In a sixth step Reynold's (1998) approach proposes to interpret the findings for the purposes of generalization and knowledge transfer, including generalizations that are relevant to other contexts of use for other audiences as well. The final step is most important for practical purposes, since it contributes to improvement. Here, the results of the above steps are used for 
identifying possible areas of improvement of the gaming simulation or its implementation. This concerns mainly the design-in-the-large, e.g. in that the interactions between the players in the simulation game improve the effectiveness of the series of strategic decisions in an organization. Yet, also from a design-in-the-small perspective the evaluation results could lead to improvements, such as including more accurate causal links in the dynamic game model.

The theory-oriented approach to evaluation is not the ultimate solution for every possible evaluation goal, since these goals can be different in different contexts. Two situations come to mind, where other approaches probably fit better (cf. Chen, 2005). The first one is in the very early stages of developing a gaming simulation. Here the goal is to test prototypes of a game with only a small sample of stakeholders where purely qualitative evaluations can be much more informative than a fully-fledged quantitative design. Yet, also here a theory-based approach can help to focus the evaluation, because it helps to identify the key questions for interviews or observations referring to actions and intended and unintended effects. A second case where the theory-based approach is sometimes less well suited, is given in decision-making contexts, where one game or simulation is to be chosen among a set of alternatives with the aim to serve a given goal in a fixed context of use with a clearly defined audience. To facilitate such a decision, a classical evaluation design using multiple experimental groups and measuring only the relevant outcome variables is often sufficient. Yet, it has to be mentioned that, although such decision-making situations are often cited as one of the most important reasons for conducting evaluations, in reality they seldom occur in a pure form (Alkin, 1985; Weiss, 1981). In the case of gaming simulation, for example, the result of a pure outcome evaluation is only applicable for decisions if one knows the conditions which brought forth these outcomes. If these are subject to variation, e.g. in cases where other audiences are to be addressed, knowledge of their influence is elementary, which again requires a consideration of mediating factors and causal mechanisms. These mediating factors are among others the interactions and consequences (effects) in their context of use for this intended audience with its particular history and interests.

To sum up the arguments from above, logic models can fulfill multiple functions in evaluation, since they constitute representations of thorough theoretical and conceptual considerations in evaluation and game design (Hense, 2004). To mention only the most important ones: First, in an early stage, they can help to identify the key factors in designing an evaluation. Secondly, they provide a frame of reference for interpreting the simulation's workings as a learning environment. Third, they help to identify areas for improvement in the simulation's design or implementation. In the following sections we will exemplify these possible merits by introducing a concrete logic model and by discussing the relevance of logic models in the context of the traditions of design in the large and design in the small.

\section{Example: Logic Model of SIMGAME}

To illustrate the application of the theory oriented evaluation approach we will describe the logic model of SIMGAME. The project "SIMGAME" was a Leonardo-da-Vinciprogram of the European Union and was carried out in 2003 and 2004. "SIMGAME" is a business simulation game for the economy lessons in secondary schools and was evaluated in about 30 schools from 6 different countries (Kriz, 2004; Kriz \& Hense, 2004). Until now, the project was the first in the German speaking area, where theory-oriented formative evaluation for business simulation games was used.

The logic model of the evaluation of "SIMGAME" is based on several sources, among others 1) current simulation game research (Faria, 2001; Garris, Ahlers \& Driskell, 2002; Hindle, 2002; Wolfe, 1997; Kriz \& Brandstaetter, 2002), 2) approaches of situated learning 
(Brown, Collins \& Duguid, 1989; Gruber, Law, Mandl \& Renkl, 1995; Hense, Mandl, \& Gräsel, 2001) - especially the so-called "problem-oriented learning" (Mandl \& Gerstenmaier, 2000) - as well as 3) on more general models for the quality of instruction and learning environments (Ditton, 2000; 2002).

The input-variables consisted not only of socio-demographic data of the participants, but also of the motivation for participation in the game, because motivation can be seen as an important factor that influences the learning results (comp. e.g. Deci \& Ryan, 1993). Theoretically, the previous knowledge, or previous experience as the case may be, can be considered as input factors (Krapp, 1997). These variables are not only relevant for the part of the pupils, but also on the part of the teacher. Furthermore, the preparation of the teacher is important. Even the quality of the simulation plays an important role.

It should be clear that the included outcome-variables for the model were those which could be used as indicators for achieving the learning objectives of the simulation game, e.g. the acceptance of the simulation game by teachers and pupils and the social, professional and methodological skills of the pupils that should improve for the pupils. Organizational changes e.g. positive effects on the class-climate were also included.

For the area of process variables the QUAIT-model (Quality of Instruction, Appropriateness, Incentives, Time) from Slavin (1996) can be used for adding several main factors, such as the usable time for learning ("time on task" in the logic model), the appropriateness of the level of difficulty of the learning input (in the logic model among others described and recorded by "felt under- and over-challenged"), as well as the quality of the instruction of the facilitator, which has to include the debriefing process, especially for simulation games,. Furthermore the interaction of the participants is a classical processvariable itself (Friedrich, Hron \& Hesse, 2001).

$>>>$ Insert Figure 1 here $<<<$

\section{Figure 1: Logic Model of SIMGAME}

All variables of the logic model should be based on research results and the corresponding theoretical concepts. Additionally, all the described factors should be operationalized, rated and, because of the derived theory-based hypothesis, analyzed in regard to their interaction. The various results of this evaluation are not reported here (comp. Kriz, Hense \& Puschert, 2004), because in this paper we intend to point out aspects of the benefits that theory-based evaluation can achieve, using "SIMGAME" as an example.

\section{Design in the Large, Design in the Small, and Logic Models}

Simon (1969) has pointed out that design means to conceive and to implement courses of action aimed at changing existing dysfunctional situations into preferred ones. This approach of "design-in-the-large" is the foundation of all forms of consulting work, training and education in the attempt to foster new ways of thinking and acting and to develop organizations (Klabbers, 2003). Gaming Simulation design as a "design-in-the-small" approach enhances a shift of existing organizational cultures and structures and in this way contributes to the "design-in the-large" process of social systems. Existing dysfunctional educational and organizational situations are changed and/or improved into preferred ones (design-in-the-large) through the design and use of simulation games (design-in-the-small).

Figure 2 shows how Greif \& Kurtz (1996) describe organizational change as designin-the-large with characteristic sequential phases and feedback loops: diagnosis, defining goals, development of change strategies, concrete planning, action and evaluation. Gaming simulation methods support the phase of diagnosis to determine the actual-condition. Gaming 
simulation helps to understand existing organizational structures and work processes by designing a present state simulation game. When playing and debriefing such a simulation, existing advantages and disadvantages of these structures can be illustrated, by fostering discourse on ideas for potential change strategies. In an organization, desired changes can be illustrated in "vision/future state simulation games" (see Ruohomäki, 2002; 2003). The knowledge that is acquired and the conclusions that are drawn can be used to define goals and concrete planning of change measures.

With gaming simulation consequences of alternative scenarios in a changed organizational structure can be tested, scored and discussed (test scenario games). Gaming simulation can further be used as an intervention tool for human resource management and organizational development in the training of specific department-related knowledge and required skills (training simulation game) and in this way support the execution of concrete change actions.

$>>$ Insert Figure 2 here $<<<$

\section{Figure 2: Greif \& Kurz model of organizational change (design-in-the-large) and possible support with Gaming Simulation (design-in-the-small)}

The whole process of gaming simulation is illustrated in Figure 3. A part of the existing situation of reality is selected as reference system for the designed simulation game (Kriz, 2003). The final aim is to change organizational structures and processes of social systems and/or to use the simulation game for education and training in order to change mental models and to foster skills of individuals within the real world ("reality"). In order to carry out this design-in-the-large, a game as an artifact is created and used as a dynamic model of reality (design-in-the-small). The game is applied through play and facilitation. By inviting stakeholders and opinion leaders to participate in the design process it becomes natural to have them contribute as agents as well as actors. Participating in designing, playing and debriefing allows the players to take part in the design-in-the-small process, while ultimately contributing to the next phase of the social system processes' design-in-the-large. Debriefing is facilitated to enhance the learning process and to apply newly gained insights, knowledge and skills within the design-in-the-small aimed at changing reality (design-in-thelarge). The secondary phase of debriefing, referred to as meta-debriefing and summative evaluation, is required in order to encourage further reflection on the linkages between design-in-the-small and design-in-the-large and to measure profits of changes in reality.

$>>>$ Insert Figure 3 here $<<<$

\section{Figure 3: The design-in-the-small process of Gaming Simulation and its support by Logic Models}

Logic models are helpful for the whole design process in various ways. By designing a game, the logic model can support the necessary process of reducing complexity. Logic models focus on achieving certain defined learning and change objectives. Therefore, they conduct the selection of the reality factors depicted in the simulation and their interdependencies. For facilitating, debriefing and meta-debriefing of the game, they provide knowledge for the interaction and the behavior of the players and facilitators on the basis of the selected process-variables. Especially simulation game didactic which has to be included in designing the facilitation of simulation games and its reflection in order to use the whole potential of the learning environment simulation game perfectly, can be derived from the logic model. On the one hand, the logic model sets a frame for operationalizing and measuring the variables as success indicators of the simulation game as well as for the 
interpretation of results in the sense of a summative evaluation. On the other hand, the logic model can also be used for ongoing optimization of development and implementation of the simulation game in the sense of formative evaluation.

Therefore the logic model has to be designed simultaneously within the first steps of a simulation model and, in an ideal case, by the same project team that is also responsible for designing the simulation game. Only this can ensure that the logic model leads to a targetoriented workflow and to a commonly shared vision of all designers, right from the beginning of the communication of all involved persons. Naturally the logic model - as well as the simulation game itself - can change during the design process, because the logic model and the model of the simulation game are deeply interlocked with each other.

For "SIMGAME" this was used to weight the project-objectives right from the beginning transparently and in regard of its importance. In a later phase interdependencies between the postulated variables could be better interpreted on the basis of the logic model and the corresponding hypotheses. Therefore, it was, for example, possible, to testify properly further optimizations for the simulation game process, or to answer the cost-output-question, i.e. among others, which of the several designed versions of "SIMGAME" leads under which conditions for which target-group to the best effects.

The advantages and practical values of the theory-based evaluation are now described with another concrete example. It has already been said that the quality of the simulation game is an important input variable for achieving the learning-objectives. It should be clear, that only to name this variable is not enough. In a further step, every variable of the logic model has to be operationalized and measured. In the case of SIMGAME, experts (in game design as well as in the game content related field of economy), stakeholders (for example representatives of federal economic chambers and of business associations) and in a reduced and in regard of the target-group adequate form teachers and pupils, have given feedback on the quality of the simulation game in the design and implementation phase several times, using a questionnaire. Therefore an appropriate list of quality criteria, based on gaming simulation research, was defined. The list of criteria shown in Table 1 (Kriz \& Hense, 2005) supported and guided the design of the simulation game, to achieve all these 50 criteria as well as possible. In this way, the theory-based approach that uses knowledge from analytical science, adds practical value to the design-in-the-small of the game and later contributes to the design-in-the-large of our educational systems by applying the simulation game in the classrooms.

\section{Table 1: SIMGAME - List of criteria for the quality of a simulation game as example for the operationalization of an input variable of the logic model}

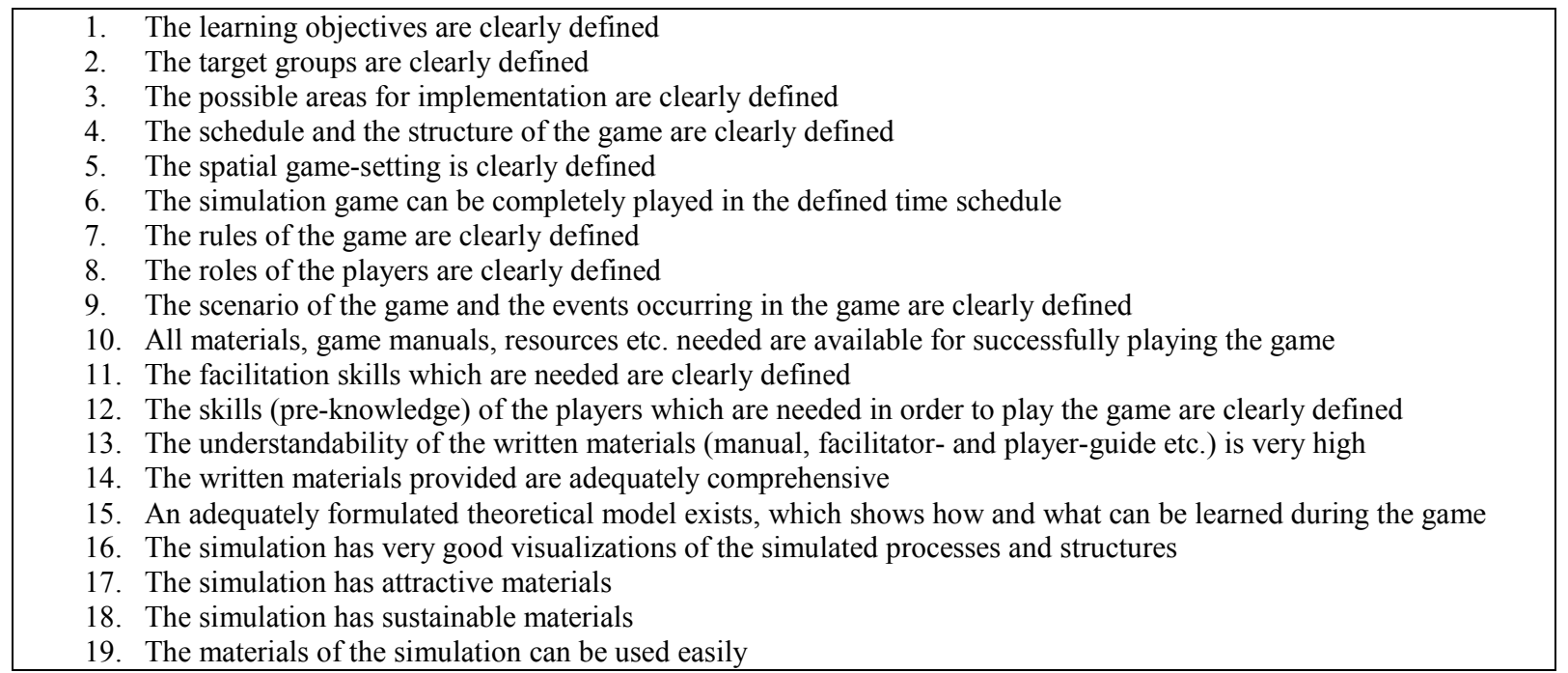


20. The design of the game supports an easy and intuitive usage of the simulation for facilitator and players (in addition, computer-based simulation games have a technically perfect and user-friendly interface)

21. The simulation can be used with adequate effort

22. The simulation results can be analyzed with adequate effort

23. The simulation includes a good reporting- and recording-system (decision-processes, changes of simulated systems and achievement of learning-objectives can be derived from adequate indicators all the time)

24. The simulation offers an adequate flexibility in the work-flow (e.g. it is possible to go one step back and decline decisions)

25. The simulation offers adequate adaptability for changed framework conditions (e.g. for smaller/larger number of participants or for longer/shorter schedule etc.) and the facilitators guide offers suggestions? hints for a flexible usage under changed framework conditions

26. The simulation offers a motivating and interesting game scenario

27. The simulation offers the players uncertainty to an adequate extent

28. The simulation activates the participants to think about interconnections of simulated systems elements

29. The simulation activates the participants to develop strategies

30. The simulation activates the participants to rate sequences and side-effects of problem-solving alternatives

31. The simulation offers a variety of interactions between participants

32. The simulation encourages a variety of perspectives and change of perspectives

33. The simulation encourages an understanding of different interest groups

34. The simulation offers an adequate link to reality for the target group; rules, roles and simulated resources correspond to real, authentic situations

35. Main processes and interconnected factors of reality are translated into the game-model correctly

36. The simulation has an adequate level of complexity for the target-group (no permanent under- or over-challenge)

37. The simulation offers several different alternatives of acting and deciding

38. There is a realistic scope of acting and deciding for the players

39. Highly skilled players/teams achieve better game results (in regard of learning objectives) in comparison to lower skilled players/teams

40. The facilitator guide contains explicit hints for briefing the simulation game (e.g. role-taking processes, basic information, guidelines for tolerated and not-tolerated behavior of the participants, etc.)

41. The instructions in the facilitator manual for gaming simulation didactic contribute to a perfect workflow (the tasks of the facilitator - e.g. the roles the facilitator has to take - during the game are clearly expressed)

42. The guidelines in the facilitator manual about debriefing ensure the learning-objectives that should be achieved (i.e. there are hints about topics, structure/schedule and methods of debriefing)

43. The guidelines about gaming simulation didactic ensure the realization of desired learning-objectives in practice (e.g. there are explicit hints about connecting the simulation with the real work processes of the target-group)

44. There are explicit hints in the manual about embedding the simulation game in a whole teaching/learning-context (e.g. in regard of the curriculum)

45. Beside the simulation game, there are complementary learning modules (i.e. in addition to the debriefing modules), which are target-group oriented and help to link the experience of the simulation game with important knowledge and competence components in the sense of a higher qualification concept (e.g. case studies, texts for teaching, professional teaching videos etc.)

46. The game is evaluated continuously and improved if needed

47. The main learning targets are achieved by the majority of the players

48. The game offers an adequate cost-outcome-relation (price, time amount, compared with suggested intervention- or learning effects)

49. The game sticks to usual ethical guidelines (e.g. human dignity is not injured, no sustaining and unjustified discrimination etc.)

50. The participants have the freedom to stop the game whenever they want (challenge by choice), if they are anxious about personal limits of dignity or unreasonable stress; in case of leaving the game, these participants have the choice to take the role or task of an observer.

\section{Bridging the Gap between Science of Design and Science of Analysis}

Simulations are used as a form of experiment in the framework of research in the tradition of analytical science. To be able to study complex structures and processes the participants have defined positions and limited room for maneuver in these experimentsimulation-games (e.g. Kriz, Hettinger, Nerl \& Gräsel, 2001). In this context, in principle the simulation is not different to the experimental/quasi-experimental method (even if it is not always a quasi-experimental study, nevertheless observations and qualitative research for example, is carried out in the context of traditional academic research). However, in the single discipline of educational psychology, which puts, among others, the optimization of learning environments in the center of research interests, gaming simulation experiments can lead to new knowledge and new theories about instruction and learning processes. These new theoretical approaches are of highly practical value in the field of gaming simulation design 
and support the definition of new logic models, which are based on scientific research and founded correlations of input-, process- and output-variables.

Game designers must use knowledge from the analytical sciences as input into their design practice, because this knowledge can contribute to build and use the designed artefacts (the game). To do so, they must of course translate the universal context-independent knowledge of analytical science research into their concrete local circumstances. As an example there is a typical science of analysis study by Stark, Gruber, Graf, Renkl \& Mandl (1996), who used the business simulation game "Jeans-Company" as an experimental setting, in order to examine among other things the influence of different instructional conditions, with forms of guided vs. non-guided problem-solving by the facilitator in relation to different groups of participants. The gained knowledge of this experiment is mainly important for the definition of relevant process-variables in logic models dealing with simulation games. The practical value are certain conclusions for the design of the facilitation of simulation games in regard to avoiding "under- and over-challenge" (therefore a varibable in the logic model shown in figure 1 and a quality criteria - nr. 36 - in table 1). In the SIMGAME project this knowledge had substantial impact on the design of the game as well as on the further development of a special teacher-training course.

In return, once a game has been designed as an artefact of a design-in-the-smallprocess by taking knowledge from analytical science into account it can be used, both for the design-in-the-large and/or as method or model in the analytical science tradition to develop and test theories (Klabbers, 2004). In addition, the design, the application and the evaluation of a simulation game as training method can be a subject of research. The formative and theory-based evaluation offers results, which contribute to the evolution of the analytical science in the sense of applied psychological-educational evaluation research. The list of quality criteria of simulation games named above is a good example for gained knowledge about simulation games as learning environments based on the results of applied analytical science, which can also be of relevance for the design science and specifically for the design of simulation games. Using this list of criteria in the evaluation of the SIMGAME project as realization of the science of design, in return offers data which can be used for the research in analytical science. Recently this correlation has been especially highly valued in the educational sciences and is required in the concept of design-based research. "Design-based research, which blends empirical educational research with theory-driven design of learning environments, is an important methodology for understanding how, when and why educational innovations work in practice. Design based research ... help us understand the relationships among educational theory, designed artefact, and practice. Design is central in efforts to foster learning, create usable knowledge, and advance theories of learning and teaching in complex settings" (Hoadley et. al., 2003, p. 5).

Especially by correlating the science of analysis and the science of design, which is the objective of our current and future integrated research- and design-projects, generalized logic models for whole types of simulation games can be defined. Some elements of the example of SIMGAME can and will surely be generalized for all rigid-rule board-based simulation games when used in schools. In every simulation game actors, rules and resources are interrelated. The interaction of the players acting upon the game model within the constraints of the game rules and the behavior of the game facilitator are therefore mediating factors that must be included in the process variables in the logic models. Knowledge from both communities, from academic analytical research and experiences from designing practice can be thus integrated in the logic model which in return supports the designing process of simulation games.

Through the implementation of the theory-oriented evaluation approach in several unique design projects in practice again universal concepts are created, which are finally the objectives of science of analysis. Furthermore, this approach can also increase the usability of simulation games in specific situations, which helps to achieve the objectives of the design 
science. Despite the term "theory"-oriented evaluation, like any other evaluation model this approach nevertheless belongs also to the science of design tradition: its primary aim is to gain evaluative knowledge on one particular gaming simulation, which in turn can be used to improve the simulation or its implementation for practical purposes. Yet, due to the intensive use of theoretical considerations, it has considerable potential for producing findings which can be transformed and accumulated into generalized knowledge. The gap of both science traditions could be bridged here.

Our detailed analysis shows that we sometimes use research terminology of the analytical science (for example, when we talk about input and output variables) to underpin our theory-based approach for the design sciences. This might well lead to criticism that possible differences may become blurred in reality through existing different methodologies and terminologies of both communities. As a matter of fact, we think that by staying with the theory-oriented approach within the standards of the analytical science, we are better recognized by our scientific community. Performing the evaluation of gaming simulation, it is definitely important to us to examine classical theory driven problems of our field (e.g. for the evaluation of learning environments) using a partially classical methodical approach of a quasi-experimental method, evaluating with common statistical techniques and interpreting by socio-scientific standards. At the same time, within the framework of the formative evaluation in real issue-driven projects (e.g. such as SIMGAME - see above) in practice our approach yields concrete results with regards to usability and optimization of the designed simulation games. This way, the participating stakeholders accept the parallel use and development of the logic model along with the simulation model. In our double role as researchers who claim scientific and domain specific findings for the development of generalized concepts and at the same time as change agents of design-in-the-large measures, we are only accepted in practice, if we can meet the expectations of the sponsors of these measures regarding outcome. In our view, the logic model that plays the main role in theory-based evaluation is well suited as a link to both communities and research traditions in the field of gaming simulation.

\section{References}

Alkin, M. C. (1985). A guide for evaluation decision makers. London: Sage.

Bickman, L. (1987). The functions of program theory. New directions for program evaluation, 33, 5-18.

Bickman, L. (Hrsg.) (1987). Using program theory in evaluation (New directions for program evaluation, Vol. 33). San Francisco: Jossey-Bass.

Brown, J. S., Collins, A. \& Duguid, P. (1989). Situated cognition and the culture of learning. Educational Researcher, 18(1), 32-42.

Chen, H. T. \& Rossi, P. H. (1983). Evaluating with sense. The theory-driven approach. Evaluation Review, 7 , 283-302.

Chen, H. T. (1990). Theory-driven evaluations. Newbury Park: Sage.

Chen, H. T. (2005). Practical program evaluation. Thousand Oaks: Sage.

Deci, L.E. \& Ryan, R.M. (1993). Die Selbstbestimmungstheorie der Motivation und ihre Bedeutung für die Pädagogik. Zeitschrift für Pädagogik, 39, 1, 223-238.

Ditton, H. (2000). Qualitätskontrolle und Qualitätssicherung in Schule und Unterricht. Ein Überblick zum Stand der empirischen Forschung. In A. Helmke, W. Hornstein \& E. Terhart (eds.), Zeitschrift für Pädagogik, 41. Beiheft (pp. 72-92). Weinheim: Beltz.

Ditton, H. (2002). Unterrichtsqualität. Konzeptionen, methodische Überlegungen und Perspektiven. Unterrichtswissenschaft, 197-212.

Faria, A. J. (2001). The changing nature of business simulation/gaming research: A brief history. Simulation \& Gaming, 32, 97-110.

Fend, H. (1997). Der Umgang mit Schule in der Adoleszenz. Göttingen: Hogrefe.

Fitz-Gibbon, C. T. \& Morris, L. L. (1975). Theory based evaluation. Evaluation Comment, 5(1), 1-4.

Friedrich, H. F., Hron, A. \& Hesse, F. W. (2001). A framework for designing and evaluating virtual seminars. European Journal of Education, 36, 157-174.

Garris, R., Ahlers, R. \& Driskell, J. E. (2002). Games, motivation, and learning: A research and practice model. Simulation \& Gaming, 33, 441-467.

Greif, S. \& Kurtz, H.-J. (1996). Handbuch Selbstorganisiertes Lernen. Göttingen: Verlag für Angewandte Psychologie. 
Gruber, H., Law, L.-C., Mandl, H. \& Renkl, A. (1995). Situated learning and transfer. In P. Reimann \& H. Spada (Eds.), Learning in humans and machines: Towards an interdisciplinary learning science (pp. 168-188). Oxford: Pergamon Press.

Hense, J. (2004). Theory-oriented evaluation of gaming simulations - the case of Simgame. In: W.C. Kriz, \& Th. Eberle, (Eds.), Bridging the Gap: Transforming Knowledge into Action through Gaming \& Simulation (pp. 339-351). München: Sagsaga.

Hense, J. \& Kriz, W.C. (2005). Theoriebasierte Evaluation und Bildungscontrolling. In: Gust, M. \& Weiß, R. (Hrsg.). Praxishandbuch Bildungscontrolling für exzellente Personalarbeit. Konzepte - Methoden Instrumente - Unternehmenspraxis. (S.). München: USP Publishing.

Hense, J., Mandl, H. \& Gräsel, C. (2001). Problemorientiertes Lernen. Warum der Unterricht mit Neuen Medien mehr sein muss als Unterrichten mit neuen Medien. Computer und Unterricht, 11(4), 66-11.

Hindle, K. (2002). A grounded theory for teaching entrepreneurship using simulation games. Simulation \& Gaming, 33, 236-241.

Hoadley, C., Baumgartner, E., Bell, P., Brophy, S., Hsi, S., Joseph, D., Orrill, C., Putambekar, S., Sandoval, W. Tabak, I., (2003). Design-Based Research: An emerging Paradigm for Educational Inquiry. Educational Researcher, 32, 1, 5-8.

Klabbers, J. H. G. (2003). Gaming and Simulation: principles of a science of design. Journal of Simulation \& Gaming, 34 (4), 569-591.

Klabbers, J. H. G. (2004). Saga about ISAGA. A retrospect and a prospect. Keynote Lecture 35th ISAGA Conference, Munich.

Krapp, A. (1997). Selbstkonzept und Leistung: Dynamik eines Zusammenspiels. In F.E. Weinert \& A. Helmke(Hrsg.), Entwicklung im Grundschulalter (S. 325-339). Weinheim: Beltz.

Kriz, W.C., Hettinger, S., Nerl. A. \& Gräsel; C. (2001). Sustainable resource management in the simulation game Fish Banks Ltd.: An experiment on the influence of systemic and social knowledge. In: A. Villems (Ed.). Bridging the Information and Knowledge Societies (p. 224-234). Tartu: Tartu University Press.

Kriz, W.C. (2003). Creating Effective Interactive Learning Environments through Gaming Simulation Design, Journal of Simulation \& Gaming, 34 (4), 117-134.

Kriz, W.C. \& Brandstätter, E. (2003). Evaluation of a Training Program for Systems-Thinking and TeamworkSkills with Gaming and Simulation. In: F. Percival, H. Godfrey, P. Laybourn \& S. Murray (Eds.), The International Simulation and Gaming Research Yearbook. Volume 11. Interactive Learning through Gaming and Simulation (p. 243-247). Edinburgh University Press.

Kriz, W.C. \& Hense, J. (2004). Evaluation of the EU-Project "Simgame" in business education. In: W.C. Kriz, \& Th. Eberle, (Eds.), Bridging the Gap: Transforming Knowledge into Action through Gaming \& Simulation (pp. 352-363). München: Sagsaga.

Kriz, W.C., Hense, J. \& Puschert, M. (2004). Endbericht zur Evaluation des EU-Projektes „Simulation betriebswirtschaftlicher Entscheidungsprozesse - Simgame“.

Kriz, W.C., Puschert, M., Karl, J. \& Dufter-Weis, A. (2004). Effective Learning through Gaming Simulation Design. In: R. Shiratori, K. Arai \& F. Kato \& (Eds.), Simulation \& Gaming (pp. 217-227). Tokyo: Springer

Kriz, W.C. \& Hense, J. (2005). Evaluation und Qualitätssicherung von Planspielen. In: U. Blötz \& Bundesinstitut für Berufsbildung BIBB Bonn (Hrsg.), Planspiele in der beruflichen Bildung (Hauptartikel im Fachbuch; 4. erweiterte Auflage). Bielefeld: Bertelsmann.

Mandl, H. \& Gerstenmaier, J. (2000). Die Kluft zwischen Wissen und Handeln. Göttingen: Hogrefe.

Reynolds, A. J. (1998). Confirmatory program evaluation: A method for strengthening causal inference. The American Journal of Evaluation, 19, 203-221.

Rogers, P. J. (2000). Causal models in program theory evaluation. New directions for evaluation, 87, 47-54.

Rossi, P., Lipsey, M. W. \& Freeman, H. (2004). Evaluation. A systematic approach. Thousand Oaks: Sage.

Ruohomäki, V. (2002). Simulation Game for Organisation Development. Development, use and evaluation of the Work Flow Game. Helsinki University of Technology. Industrial Management and Work and Organizational Psychology. Dissertation.

Ruohomäki, V. (2003). Simulation gaming for organizational development. Journal of Simulation \& Gaming, 34, 531-549.

Simon, H. (1969). The sciences of the artificial. Boston: MIT Press.

Slavin, R.E. (1996). Education for all. Lisse: Swets \& Zeitlinger.

Stark, R., Gruber, H., Graf, M. Renkl, A. \& Mandl, H. (1996). Komplexes Lernen in der kaufmännischen Erstausbildung: Kognitive und motivationale Aspekte. Zeitschrift für Berufs- und Wirtschaftspädagogik, Beiheft 13, 23-36.

Suchman, E. A. (1967). Evaluative research. Principles and practices in public service and social action programs. New York: Russel Sage Foundation.

Weiss, C. H. (1972). Evaluation research: Methods of assessing program effectiveness. Englewood Cliffs, NJ: Prentice-Hall.

Weiss, C. H. (1997). Theory-based evaluation: Past, present, and future. New Directions for Evaluation, 76, 4156. 
Wholey, J., S. (1987). Evaluability assessment. Developing program theory. New directions for program evaluation, 33, 77-92.

Wolfe, J. (1997). The effectiveness of business games in strategic management course work. Simulation \& Gaming, 28(4), 360-376.

\section{Authors}

Willy Kriz, University of Applied Sciences Vorarlberg, Department Management and Research Methods, Dornbirn, Austria, e-mail: willy.kriz@fhv.at

Jan Ulrich Hense, Ludwig Maximilians University, Department Psychology, Munich, Germany, e-mail: hense@emp.paed.uni-muenchen.de 
Figure 1

\begin{tabular}{|c|c|c|c|}
\hline Input & Process & $\begin{array}{c}\text { Short-term } \\
\text { outcomes }\end{array}$ & $\begin{array}{c}\text { Long-term } \\
\text { outcomes }\end{array}$ \\
\hline $\begin{array}{l}\text { Students } \\
\text { - previous knowledge } \\
\text { - previous experience } \\
\text { - motivation } \\
\text { - expectancies } \\
\text { - age } \\
\text { - gender }\end{array}$ & $\begin{array}{l}\text { Individual learning } \\
\text { - intensity of involvement } \\
\text { - over-/underchallenged }\end{array}$ & $\begin{array}{l}\text { Learning effects } \\
\text { - cognitive } \\
\text { (knowledge) } \\
\text { - } \text { social } \\
\text { - motivational }\end{array}$ & $\begin{array}{l}\text { Individual } \\
\text { outcomes } \\
\text { - school success }\end{array}$ \\
\hline $\begin{array}{l}\text { Gaming simulation } \\
\text { - content quality } \\
\text { - game/simulation } \\
\text { quality }\end{array}$ & $\begin{array}{l}\text { Interaction with the game } \\
\text { - time-on-task } \\
\text { - adequacy of contents } \\
\text { - debriefing }\end{array}$ & $\begin{array}{l}\text { Acceptance } \\
\text { (students) } \\
\text { - of the game } \\
\text { - of the method }\end{array}$ & success \\
\hline $\begin{array}{l}\text { Teacher } \\
\text { - } \text { training experience } \\
\text { with gaming } \\
\text { simulations } \\
\text { - motivation } \\
\text { - expectancies } \\
\text { - preparation }\end{array}$ & $\begin{array}{l}\text { Social learning } \\
\text { - student-student } \\
\text { - intensity } \\
\text { - quality } \\
\text { - student-teacher } \\
\text { - instruction } \\
\text { - support }\end{array}$ & $\begin{array}{l}\text { - of the game } \\
\text { - of the method } \\
\begin{array}{l}\text { Organisational } \\
\text { effects } \\
\text { - class climate }\end{array}\end{array}$ & $\begin{array}{l}\text { Project } \\
\text { - implementation } \\
\text { of the game } \\
\text { - dissemination } \\
\text { of the method }\end{array}$ \\
\hline
\end{tabular}


Figure 2

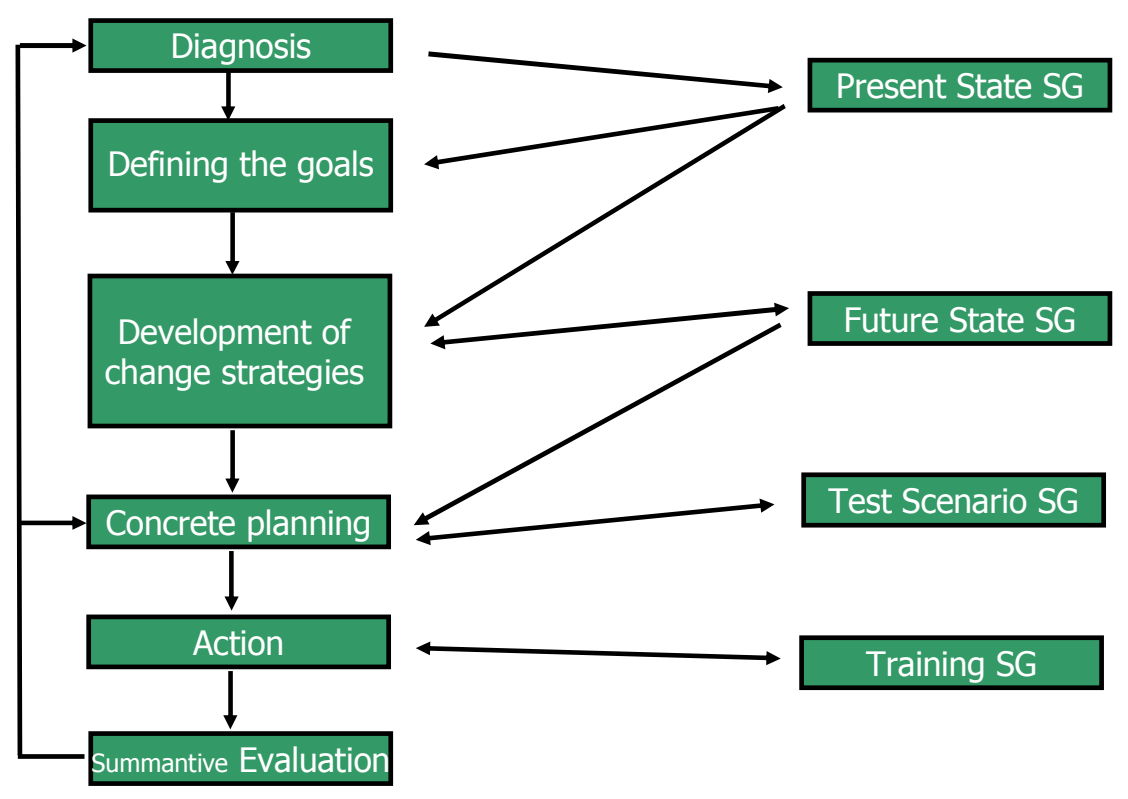


Figure 3

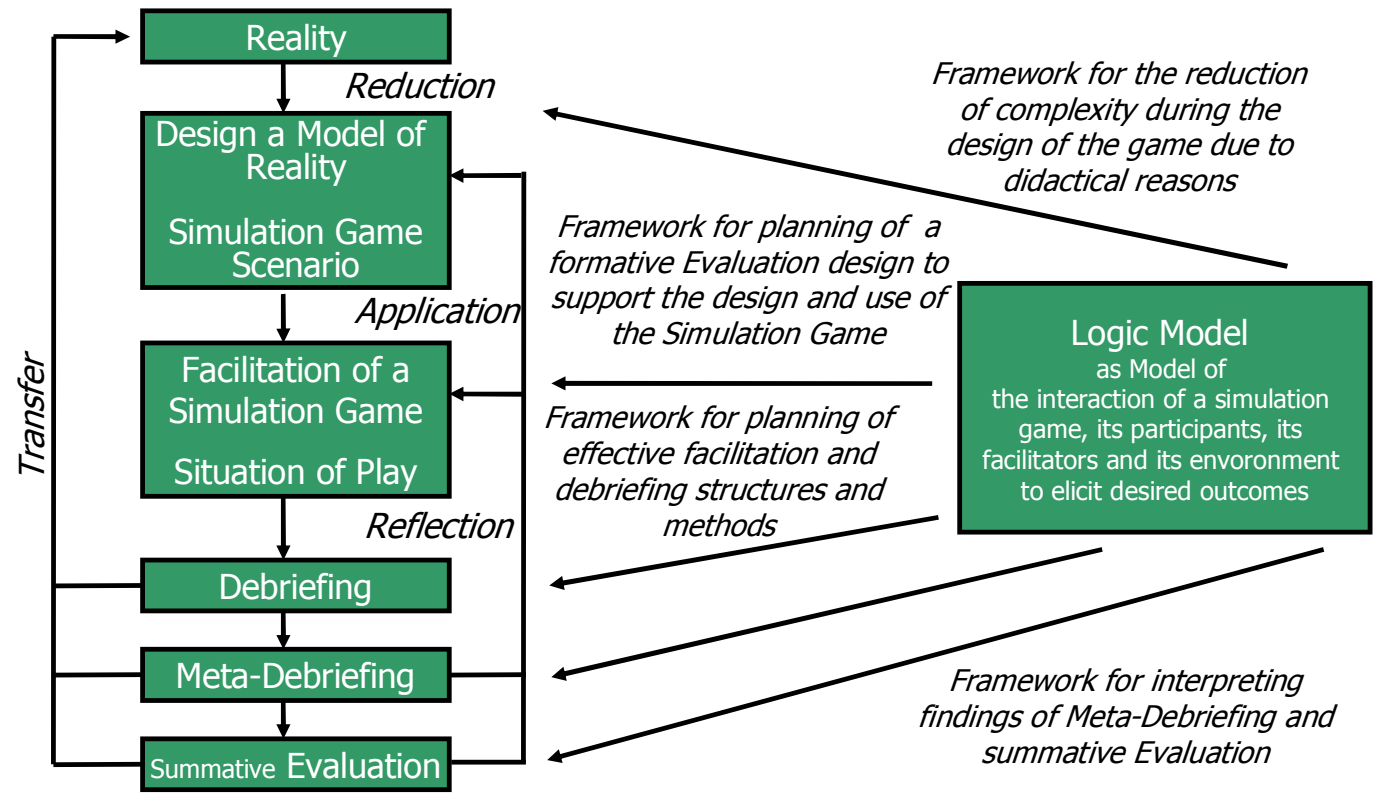

